http://jmscr.igmpublication.org/home/

ISSN (e)-2347-176x ISSN (p) 2455-0450

crossref DOI: https://dx.doi.org/10.18535/jmscr/v7i8.129

Journal Of Medical Science And Clinical Research

\title{
Infiltrating Ductal Breast Carcinoma: Correlation of Cytological Grading with Histopathological Grading and regional lymphnode status
}

\author{
Authors \\ Dr Akkem Vijaya Jyothi ${ }^{1}$, Dr. B Nagaraja ${ }^{2 *}$ \\ ${ }^{1}$ Assistant Professor, Department of Pathology, Government Medical College, Kadapa \\ ${ }^{2}$ Associate Professor, Department of Pathology, Government Medical College, Kadapa \\ *Corresponding Author \\ Dr B Nagaraja \\ Associate Professor, Department of Pathology, Government Medical College, Kadapa, India
}

\begin{abstract}
In the initial evaluation of breast lumps, Fine Needle Aspiration (FNA) is a proven diagnostic technique. Aim of the study is to grade the infiltrating ductal carcinoma of breast by both cytologically and histologically and to correlate its grading. A total of 44 cases with a cytological diagnosis of invasive ductal carcinoma subsequently proved on histology were studied. These were graded according to Robinson's cytological grading (RCG) and Elston's modification of Bloom Richardson's histological grading system. Statistical analysis was done using $\chi^{2}$ test. Multiple regression analysis was done to assess the significance of each cytological and histological parameter. There were 22(50\%), 19(43.1\%) and $3(6.8 \%)$ cases of grade I, II and III ductal carcinomas respectively graded cytologically and 19(43.2\%), $20(45.5 \%)$ and 5(11.4\%) cases of ductal carcinomas graded I, II and III histologically. Overall, in 37 cases $(84 \%)$ the cytological grade correlated with the histological grade and in 7 cases (18\%) discrepancy was noted. There was a significant association $(p<0.05)$ between the cytological and histological grading. This study showed that the extent of cell size, cell uniformity, nucleoli were the most influential features. $68 \%$ of grade I tumors 53\% of grade II and 100\% of grade III tumors showed lymphnode metastasis. Lymph node metastasis was seen irrespective of the grade of the tumor. To conclude grading act as powerful predictor of tumor aggressiveness; should thus be addressed in pathological analysis of breast carcinoma as it is simple and feasible.

Keywords: Breast carcinoma, Cytological grading, Cytohistological correlation, Histological grading.
\end{abstract}

\section{Introduction}

In developing countries, the incidence of breast carcinoma is gradually increasing and approaching to replace cervical carcinoma as a leading malignancy among women including India $^{[1]}$ The reason attributable for increasing the incidence is the shift towards Western life style and the incidence can be reduced by making the awareness about signs and symptoms of breast lesions and its early detection by regular selfexamination of breast. $^{[2]}$ The management of breast cancer depends on various prognostic parameters, example; tumor histpathological grading, lymphnode status, estrogen receptor status and cell proliferation index ${ }^{[3]}$. Most of these parameters are determined after it has been 
excised from the body on the histopathological examination only. However, the ideal situation would be to characterize the tumor while it is still in vivo so that preoperatively an appropriate therapy can be designed ${ }^{[4]}$. While conservative therapy is recommended for low grade breast carcinoma. Neoadjuvant chemotherapy (NAT) and radiotherapy are becoming increasingly popular modes of treatment for high grade breast carcinoma. In recent years, Attempts have been made to determine various prognostic parameters on FNA material. ${ }^{[5,6]}$ Fine needle aspiration cytology (FNAC) is increasingly being used for the pre-operative diagnosis of breast carcinoma. In our present study we report to compare cytological grading of ductal carcinoma by Robinson cytological grading on FNA material and histological grading by Elston's modification of Bloom Richardson method on surgically resected specimens. Palpable lymph nodes were also assessed for metastatic deposits.

\section{Materials and Methods}

The study was a prospective and retrospective study done over a period of two and half years in the department of pathology, southern part of Andhra Pradesh. A total of 44 cases were included which were diagnosed as infiltrating ductal carcinoma on FNA, and all the clinical data regarding were collected. FNA procedure was performed using multidirectional technique with 23 gauge needle attached to $10 \mathrm{ml}$ syringe with Franzer type syringe holder. Aspirated material was expressed on to the slides, smears were prepared and fixed in alcohol and stained with Haematoxylin \& Eosin (H\&E) and Papanicolaou stain (Pap stain). Air dried smears were also prepared and stained with May Grunwald Giemsa (MGG) stain. Inclusion criteria was only the cases having six or more epithelial cell clusters were studied as this is the minimum criteria for adequacy ${ }^{[5]}$. The smears were evaluated based on grading system described by Robinson [6] presented in (Table 1). The values between 1 and 3 was given to each parameter in table 1 . The scores for each of the 6 parameters were added together to give a total score for each case, where the final score ranged between 6 and 18 .

Surgical specimens were obtained and the cases with histological diagnosis of infiltrating ductal carcinoma whose cytological diagnosis was infiltrating ductal carcinoma were taken. Samples were routinely processed and stained with $H \& E$. Axillary lymph nodes were also similarly processed. Histological grading of H\&E stained tissue sections was done by Nottingham modification of Scarff-Bloom Richardson method, where three parameters were taken into consideration: nuclear pleomorphism, number of mitosis and degree of tubule formation. Mitotic counts were scored using Olympus microscope with a field diameter $0.59 \mathrm{~mm}$. Each parameter was scored between 1 and 3 . Thus the overall score for each case ranged between 3 and 9 .

Statistical analysis was performed using the SPSS statistical software package, version $19 . \mathrm{X}^{2}$ test used to compare and to examine the degree of correlation between the cytological and histpathological grades. P value of less than 0.05 was considered as statistically significant.

\section{Results}

Majority of the tumors were grade I on cytology $(50 \%)$. The next commoner was grade II tumors (43\%) and only $6.8 \%$ were of cytological grade III. On histopathological grading, 19 (43\%) tumors gradeI, $20(46 \%)$ tumors grade II and $5(11 \%)$ grade III. (Figures 1-3) shows the cytological features found for the Robinson grades I to III. (Table 2) shows the comparison of cytological grade with histopathological grade. The concordance rate between grade I tumors in cytology and histopathology was $82 \%$, while for grade II was $84 \%$ and $100 \%$ for grade III. In the present study the correlation between cytological grade and histopathological grade was statistically significant ( $p$ value $<0.05$ ) Overall sensitivity was $88.7 \%$. Significant correlation between cytological grade and histological grade was obtained in 37 $(84 \%)$ cases and in seven cases $(15.9 \%)$ there was 
a discrepancy. Out of the seven cases, six cases were upgraded and one case downgraded on histopathology.

Data from (Table 3) shows that $68 \%$ of grade I tumors $53 \%$ of grade II and $100 \%$ of grade III tumors showed lymphnode metastasis. Lymph node metastasis was seen irrespective of the grade of the tumor. The grade of the tumor showed no significant association $(p>0.05)$ with the lymph node involvement although all the grade III tumors showed metastasis.

Table 1: Robinson's Cytological Grading of Breast Carcinomas on FNA Material

\begin{tabular}{|l|c|c|c|}
\hline Cell features & Score I & Score II & Score III \\
\hline Dissociation & Cells mostly in clusters & $\begin{array}{c}\text { Mixture of singles and } \\
\text { clusters }\end{array}$ & Cells mostly in single \\
\hline Cell size & $1-2 \mathrm{X}$ RBC & $3-4$ X RBC & Pleomorphic \\
\hline Cell uniformity & Monomorphic & Mildly pleomorphic & Prominent or Pleomorphic \\
\hline Nucleoli & Indistinct & Noticeable & Buds or clefts \\
\hline Nuclear margin & Smooth & $\begin{array}{c}\text { Slightly } \\
\text { irregular/folds/grooves }\end{array}$ & Clumped and cleared \\
\hline Chromatin & Vesicular & Granular & Promolar \\
\hline
\end{tabular}

Table 2: Correlation of Cytological Grade with Histopathological Grade

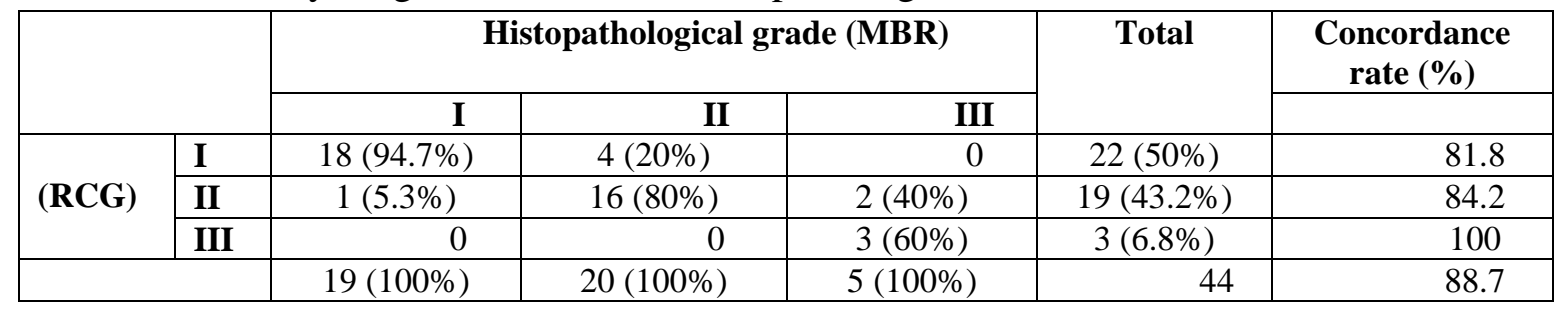

Table 3: Correlation of Cytological Grade and Axillary Lymphnode Status

\begin{tabular}{|c|c|c|c|c|}
\hline & \multicolumn{3}{|c|}{ Lymphnodes } \\
\hline & & Positive & Negative & Total \\
\hline \multirow{3}{*}{$\begin{array}{l}\text { Cytological } \\
\text { grade }\end{array}$} & 1 & $15(68.1 \%)$ & $7(31.8 \%)$ & 22 \\
\hline & 2 & $10(52.6 \%)$ & $9(47.3 \%)$ & 19 \\
\hline & 3 & 3 & 0 & 3 \\
\hline \multicolumn{2}{|c|}{ Total } & $28(63.6 \%)$ & $16(36.3 \%)$ & 44 \\
\hline
\end{tabular}

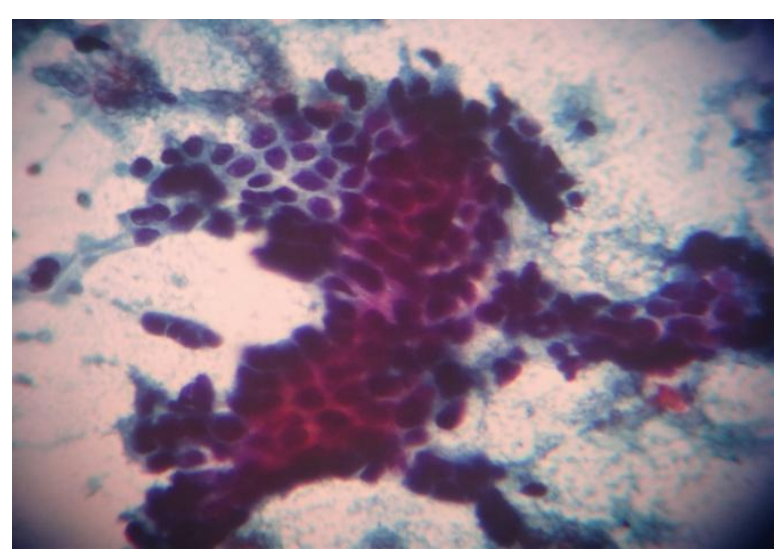

Figure 1: Photomicrograph of cytological grade I duct cell carcinoma. The cells are in cohesive clusters with enlarged mild pleomorphic nuclei, smooth nuclear margin and inconspicuous nucleoli. [Pap,x400]

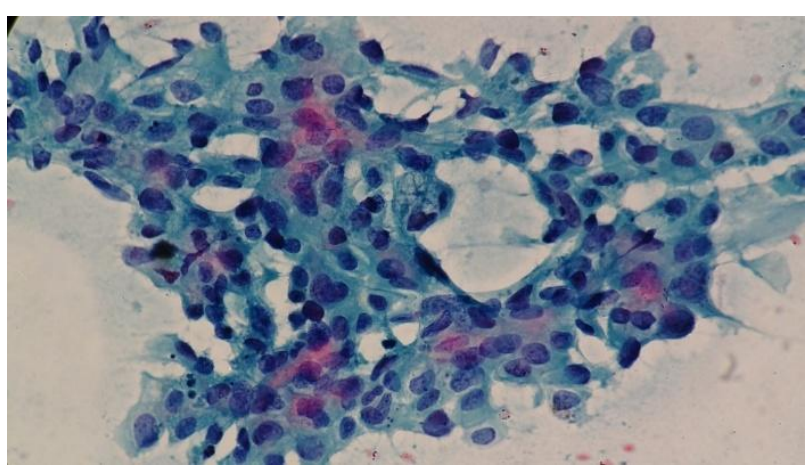

Figure 2: Photomicrograph of cytological grade II duct cell carcinoma. Cells are in loose clusters with dispersed cells. Nuclei are three to four times the erythrocyte, with smooth margin and single prominent nucleoli. [Pap,x 400] 


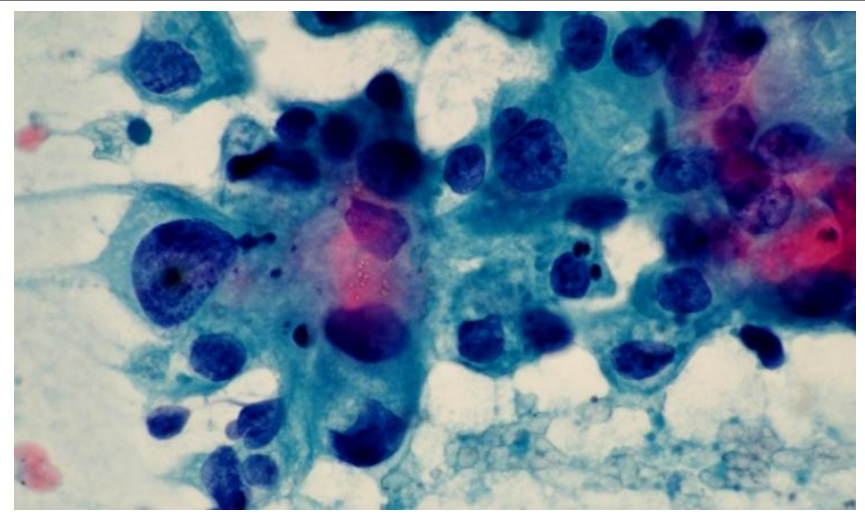

Figure 3: Photomicrograph of cytological grade III duct cell carcinoma. Cells are in singles with coarsely granular chromatin, with irregular folded nuclear margins and very prominent nucleoli. [Pap, X400]

\section{Discussion}

In the review of literature a number of studies have confirmed the prognostic value of histopathological grading in invasive ductal carcinoma. ${ }^{[7,8]}$. On FNA samples a variety of techniques have been described for grading invasive carcinomas to determine the best therapy for a particular given case. The National cancer institute which were sponsored conference on the "uniform approach to breast FNA biopsy" has also recommended that tumor grading on FNA material should be incorporated in FNA reports for prognostication. ${ }^{[9] .}$ Based on cytological studies a wide number of grading systems were developed with results similar to those obtained from histopatholological sections. Among those, the grading system developed by Robinson was very well correlated with histopathological grading system that is Scarff Bloom Richardson method, which was proved by various studies ${ }^{[6,10-}$ ${ }^{15]}$. The purpose of cytological prognostic grading is to identify fast growing tumors (grade III), which are more likely to respond to chemotherapy than low grade. In the present study, there was a statistically significant correlation seen in 37 ( $84 \%$ ) cases. Overall concordance rate was $88.7 \%$. In other studies with total number of cases less than 70 , showed the concordance rates varied

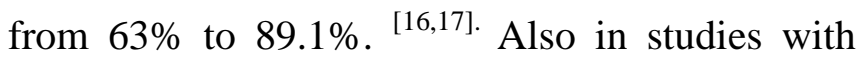
equal to or more than 70 cases, the concordance rates varied from $43.3 \%$ to $90.7 \% .{ }^{[18]}$ In present study grading systems showed stronger correlations in higher grades. Out of all cases which were studied the seven cases showed discrepancy, out of which six cases were upgraded and one case downgraded on histopathology. It may be due to the observer variability when assigning the grade. Nuclear margins (smooth, slightly irregular, folds, grooves, clefts, budding) and chromatin pattern (granular/clumping and clearing) are some of the features where observer variability is more likely. This may also be attributable to tumor heterogeneity and large tumor size. When tumor size is large, the most undifferentiated areas of tumor may not be represented in our routine FNAs. In contrast in histopathological examination, the entire tumor is sampled, so that it will be allowing for evaluation of the most undifferentiated areas.

Multiple regression analysis of cytological features was used to assess the significance of each cytological parameter, where the cell size, uniformity and nucleoli were the most influential factors. In all other various studies grade II tumors were most common but in our present study grade I tumors were commonly seen, similar to the study of Sultana $\mathrm{T}$ et $\mathrm{al}^{[14]}$. This may be due to the early presentation of patients because of increased awareness of breast cancer in and around of study location.

In breast carcinoma, lymph node metastasis is a factor of known prognostic significance. Patients with definitive lymph node involvement have highly significant poor prognosis than the patients those are without nodal metastasis. ${ }^{[19]}$. A woman who presents breast cancer with negative lymphnodes have $70-80 \%$ likelihood of long term survival without metastasis, while the patients who present with regional lymphnode metastasis have approximately an $80 \%$ likelihood of developing distant metastatic disease ${ }^{[20]}$. In the present study 28(63\%) out of 44 cases had lymph node metastasis. There was $68.2 \%$ of grade I, $52.6 \%$ of grade II, $100 \%$ of grade III tumors showed metastasis. There was no significant 
association between the grade of the tumor and lymph node metastasis, but grade III tumors had a high rate of metastasis in concordance with Dash et al study. ${ }^{[21]}$

\section{Conclusion}

To conclude from this study that FNAC can be a simple, rapid and effective valid tool for the first line diagnostic modality in ductal carcinomas of breast. The Robinson cytological grading was found to be sensitive and easily reproducible. The RBS grading system is very simple. The information obtained is of clinical use and also used for prognostic value especially when combined with mammographic findings. Thus it is suggested that effort should be made to include the cytological grading in all the FNAC reports of breast cancers, so that an appropriate decision regarding the preoperative therapy can be taken and the unnecessary treatment of low grade cancers is avoided.

\section{References}

1. Murthy NS, Chaudhry K, Nadayil D, Agarwal UK, Saxena S. Changing trends in incidence of breast cancer: Indian scenario. Indian J Cancer 2009; 46:73-4.

2. Bhatt JV, Shah JM, Shah FS. Pathophysiology of breast lesions: vision beyond the clinical eye. J Appl Basic Med Sci 2002; 4:81-4.

3. Khan N, Afroz N, Rana F, Khan MA. Role of cytologic grading in prognostication of invasive breast carcinoma. J Cytol 2009; 26(2): 65-8.

4. Wani FA, Bharadwaj S, Kumar D, Katoch P. Cytological grading of breast cancers and comparative evaluation of two grading systems. J Cytol 2010; 27(2):55-8.

5. Sinha SK, Sinha N, Bandyopadhyay R, Mondal SK. Robinson's cytological grading on aspirates of breast carcinoma: Correlation with Bloom Richardson's histological grading. J Cytol 2009; 26(4):140-3.
6. Robinson IA, McKee G, Nicholson A, D'Arey J, Jackson PA, Cook MG, et al. Prognostic value of cytological grading of fine-needle aspirates from breast carcinomas. Lancet 1994; 343:947-9.

7. Latinovie L, Heinze G, Birner $P$, Samonigy H, Hausmaninger H, Kubista E et al. Prognostic relevance of three histological grading methods in breast cancer. Int J Oncol 2001;19:1271-7.

8. Simpson JF, Grey R, Dressler LG, Cobau $\mathrm{CD}$, Falkson CI, Gilchrist $\mathrm{KW}$ et al. Prognostic value of histologic grade and proliferative activity in axillary node positive breast cancer: Results from Eastern Cooperative Oncology Group Comparision Study EST4189. J Clin Oncol 2000;18:2059-69.

9. The uniform approach to breast Fineneedle aspiration biopsy. National Cancer Institute Fine-Needle Aspiration of Breast Workshop Subcommittees. Diag Cytopathol 1997; 16(4):295-311.

10. Hemachandran M, Nijhawan R, Joshi K. Cytological grading, apoptosis and Bcl-2 protein expression in breast cancer. Diagn Cytopathol 2002; 26:356-9.

11. Khan MZ, Haleem A, Al Hassani H, Kfoury H. Cytopathological grading, as a predictor of histopathological grade, in ductal Carcinoma (NOS) of breast, on airdried Diff-Quick smears. Diagn Cytopathol 2003; 29:185-93.

12. Robles-Frias A, Gonzalez-Campora R, Martinez-Parra D, Robles-Frias M, Vazquenz-Cerezuda T, Otal-Salaverric, et al. Robinson cytologic grading of Invasive Ductal Breast Carcinoma Correlation with Histologic Grading and regional lymph node metastasis. Acta Cytol 2005; 49:14953.

13. Meena SP, Hemrajani DK, Joshi N. A Comparative and evaluative study of cytological and histological grading system profile in malignant neoplasm of 
breast - an important prognostic factor. Indian J Pathol Microbiol 2006; 49(2):199202.

14. Sultana T, Rahman AJ. Cytological grading of duct cell carcinoma, NOS of breast and its correlation with histological grading. Bangladesh Med Res Counc Bull 2006; 32(2):49-54.

15. Rekha TS, Nandini NM, Dhar M. Validity of Different Cytological Grading Systems of Breast carcinoma - a Hospital - based Study in South India. Asian Pacific J Cancer Prev2011; 12:3013-6.

16. Das AK, Kapila K, Dinda AK, Verma K. Comparative evaluation of grading of breast carcinomas in fine needle aspirates by two methods. Indian J Med Res 2003; 118:247-50.

17. Chhabra S, Singh PK, Agarwal A, Bhagoliwal A, Singh SN. Cytological Grading of Breast Carcinoma-A Multivariate Regression Analysis. J Cytol 2005; 22(2):62-5.

18. Pandit AA, Parekh HJ. Cytologic grading of breast carcinoma. Comparison of four grading systems. J Cytol 2000; 17:39-44.

19. Carter CL, Allen C, Henson DE. Relation of tumor size, lymph node status and survival in 24,740 breast cancer cases. Cancer 1989; 63:181-7.

20. Taniguchi E, Yang Q, Tang W, Nakamura Y, Shan L, Nakamura M, et al. Cytologic grading of invasive breast carcinoma. Correlation with clinicopathologic variables and predictive value of nodal metastasis. Acta Cytol 2000; 44:587-91.

21. Dash A, Mohanty R, Mallik R, Dash K. Aspiration smear pattern as a predictor of biological behavior in breast carcinoma. $\mathrm{J}$ Cytol 2005; 22:19-21. 